\title{
TLR2 AND TLR4 EXPRESSION ON BLOOD MONOCYTES AND GRANULOCYTES OF CARDIAC SURGICAL PATIENTS IS NOT AFFECTED BY THE USE OF CARDIOPULMONARY BYPASS
}

\author{
Jan Krejsek', Martina Koláčková', Jiřri Mand'ák ${ }^{2}$, Pavel Kuneš², Zdeňka Holubcová2, Drahomíra Holmannová1, \\ Mouhammed AbuAttieh ${ }^{1}$, Ctirad Andrýs ${ }^{1}$
}

Charles University in Prague, Faculty of Medicine and University Hospital in Hradec Králové, Czech Republic: Department of Clinical Immunology ${ }^{1}$, Department of Cardiac Surgery ${ }^{2}$

\begin{abstract}
Summary: Cardiac surgery is inseparably linked to the activation of innate immunity cells recognizing danger signals of both endogenous and exogenous origin via pattern recognition receptors such as TLR receptors. Therefore, we followed by flow cytometry TLR2 and TLR4 expression on blood monocytes and granulocytes of patients who underwent coronary artery bypass grafting using beating heart surgery (off-pump, $\mathrm{n}=34$ ), with use of standard cardiopulmonary bypass (CPB), (on-pump, $\mathrm{n}=30$ ), and miniinvasive $\mathrm{CPB}$ (mini on-pump, $\mathrm{n}=25$ ), respectively, before, during surgery, and up to 7th postoperative day. TLR2 and TLR4 expression both on monocytes and granulocytes was significantly diminished already at the end of CPB being highly significantly decreased at the end of surgery in all patients' groups. TLR2 and TLR4 expression reached preoperative value at the 1st postoperative day being significantly higher at the 3rd postoperative day. Using intracellular staining we found the peak of TLR2 and TLR4 expression inside of monocytes and granulocytes at the first postoperative day in a subgroup of on-pump patients. In conclusion, TLR2 and TLR4 expression is significantly modulated in patients undergoing coronary artery bypass grafting as a part of adaptive homeostatic mechanisms induced by major surgery. The very surgical trauma is responsible for TLR2 and TLR4 modulation. Surprisingly, cardiopulmonary bypass itself was little contributing to the modulation of TLR2 and TLR4 expression.
\end{abstract}

Key words: Cardiac surgery; Inflammation; TLR2 and TLR4 expression; Flow cytometry; Dynamics

\section{Introduction}

Numerous potentially harmful events that may result in onset of an overt inflammatory response are inevitably induced in the course of cardiac surgery. Nowadays it is well established that the protective potential of the inflammatory response is inseparably linked with its destructive counterpart, which might inflict unwanted damage of any body structure.

This response may lead to postoperative complications, including the systemic inflammatory response syndrome, multiple organ dysfunction, and failure, and in a small proportion of patients, even to the death $(1,2)$. Cardiopulmonary bypass $(\mathrm{CPB})$ is considered to be the trigger of immune cells activation induced by their contact with artificial surfaces of tubing and oxygenators, and also by no turbulent blood flow. In addition, hypoperfusion of critical body organs such as heart and gut is linked to the pronounced ischemia reperfusion damage of these vital organs (3). The effort to remove the harmful effect of the conventional $\mathrm{CPB}$ has led to a development of modified (mini) CPB. Mini CPB that has recently been introduced and successfully used, is designed to reduce blood cell activation (4). It provides decreased area of extracorporeal circuit, reduces priming, and also lessens air-blood interface. Another favourable feature of mini CPB is a biocompatible coating that induces higher tolerance of blood cells (5). In spite the fact that the general consensus has not been reached yet, it seems that beating heart surgery is the most physiological approach to surgical myocardial revascularization, coronary artery bypass surgery $(\mathrm{CABG})$. The beating heart surgery is at least avoiding the massive proinflammatory stimuli immanently associated with the use of CPB. Furthermore, pulsate blood flow is maintained with better perfusion of vital body organs thus ameliorating ischemia/reperfusion injury (6).

The inflammatory response in cardiac surgical patients is induced by the exposition of body components, both humoral and cellular to the danger patterns, either exogenous or endogenous origin. Microbial pathogen - associated molecular patterns (PAMPs) and endogenous molecules created upon tissue injury, since called damage-associated molecular patterns (DAMPs), signal the threat of either infection or injury to the host, independently of their non-self or self identity (7). Danger patterns, regardless their origin, are identified by the set of evolutionary highly conserved receptors named pattern recognition receptors (PRR) with subsequent activation of several intracellular activation pathways, culminating predominantly in NFKB transcrip- 
tion factor activation. $\mathrm{NF} \kappa \mathrm{B}$ translocates to the nucleus and mediates an increase on inflammatory cytokine gene expression, leading to pro-inflammatory response. PRR receptors are present within the tissues as membrane glycoproteins, which are expressed on either the outer or inner surfaces of the cellular membrane systems. The broadest expression of all PRR receptors has been proved on innate immunity cells. This heterogeneous cell population comprising dendritic cells, macrophages, and monocytes, is strategically scattered throughout all tissues, including blood and other body fluids, where it serves as sentinel cells that reliably identify, via their PRR receptors, any adverse, potentially noxious, stimuli (8).

The family of Toll-like receptors (TLRs) is prominent. TLRs, of which there are currently 10 described in humans, binding to a range of PAMPs. TLR2 functions a heterodimer with either TLR1 or TLR6 and senses lipopeptides from bacteria. TLR4 binds to lipopolysaccharide of gram-negative bacteria complexed to LBP plasma protein with essential participation of another membrane protein CD14. In addition to the recognition of PAMPs, TLR2 and TLR4 have also been shown to recognise endogenous ligands DAMPs. TLR2 and TLR4 are membrane expressed and have a wide range of putative endogenous ligands which comprise HSP stress proteins, high mobility group box 1 (HMGB1) nucleoprotein and breakdown products of fibronectin, heparansulfate, and hyaluronic acid. All these danger signals are inseparable linked to trauma including surgical injury (9). The broad expression profile of TLRs and their ability to recognise many ligands that are released predominantly as a consequence of tissue injury positions TLR dependent signalling as a rapid response mechanism to tissue damage (10).

Major surgery, including cardiac surgical operations, is characterized by massive generation of DAMPs and the different exposure to PAMPs reflecting the type of surgery being more pronounced in abdominal surgery. Surprisingly, the modulation of TLR sensing system by surgery is, in comparison other clinical situation, still poorly investigated. This is true especially in cardiac surgery. We described the dynamics or TLR2 and TLR4 expression on blood monocytes and granulocytes of cardiac surgical patients undergoing $\mathrm{CABG}$ either with or without $\mathrm{CPB}$ in our previous work (11). Therefore, this observational study is aimed to substantiate our previous findings. Another aim of this study is to reconcile which surgical approach, either beating heart surgery, or cardiac surgery with CPB or modified $\mathrm{CPB}$, respectively, reveals more pronounced effect on TLR expression.

\section{Patients and Methods}

\section{Patients}

Eighty-nine patients referred to the first-time coronary artery bypass grafting (CABG) surgery were enrolled in this study. All patients were well informed about purpose of this study and they confirmed their unconstrained participation by a written consent. The study project was approved by the Ethics Committee of the University Hospital in Hradec Kralove, Czech Republic. They underwent either conventional myocardial revascularization with CPB and cardioplegic arrest of the heart (on-pump), or with minimally invasive CPB (mini on-pump) or beating heart surgery without CPB (off-pump). Exclusion criteria consisted of acute inflammation, urgent operation, reoperation, combined operations, operative risk more than 5\% (according to logistic Euroscore), preoperative level of serum creatinine above $130 \mu \mathrm{mol} / \mathrm{L}$, hepatic disease, and malignancies. The demographic and preoperative data of our patients are shown in Table 1.

$$
\begin{gathered}
\text { Methods } \\
\text { Coronary Artery Bypass Grafting } \\
\text { with Conventional Cardiopulmonary Bypass (CPB), } \\
\text { on-pump technique }
\end{gathered}
$$

All operations were performed via median sternotomy. Heparin was administered intravenously $(4 \mathrm{mg} / \mathrm{kg}$ of body weight) to maintain an activated clotting time (ACT) above 480 s during the CPB run. The ascending aorta was cannulated by standard aortic cannula and a two-stage venous cannula was placed via the right atrium into the inferior vena cava. The CPB circuit was established using noncoated tubing, a hard shell venous reservoir (Dideco SrL, Mirandola, Italy), a cardiotomy suction device, a hollow fiber membrane oxygenator (Dideco SrL, Mirandola, Italy), a roller pump (Stöckert Instrumente $\mathrm{GmBH}$, München, Germany) and $40.0 \mu \mathrm{m}$ arterial line filter (Dideco SrL, Mirandola, Italy). The extracorporeal circuit was primed with $500 \mathrm{ml}$ of Ringer's lactate, $500 \mathrm{ml}$ of Rheodextran (Rheomacrodex), 5,000 IU Heparin, $80 \mathrm{ml}$ of Natrium Bicarbonate $\left(\mathrm{NaHCO}_{3} 8.4 \%\right), 20 \mathrm{ml}$ of $10 \%$ Magnesium Sulphate, and Mannitol (at $1 \mathrm{~g} / \mathrm{kg}$ of body weight) and calculated to reach hematocrit level above 0.22 . The non-pulsatile pump flow was maintained at targeted rate of $2.41 / \mathrm{min} / \mathrm{m}^{2}$. At the initiation of $\mathrm{CPB}$, cardiac arrest was achieved by administration of cold blood cardioplegic solution (St. Thomas solution, Ardeapharma, Sevetin, Czech Republic; ratio $4: 1$ ) in antegrade fashion (10-15 $\mathrm{ml} / \mathrm{kg}$ of body weight). The heart was cooled topically by cold water and cardioplegia administered repeatedly every 25 minutes. The patient's temperature was allowed to drift to $34-35^{\circ} \mathrm{C}$. Distal anastomoses were performed on the arrested heart in standard manner (every patient received left internal mammary artery graft and different number of saphenous vein grafts). Proximal anastomoses were accomplished while a partial occlusion aortic clamp was applied on the already beating heart. After the termination of $\mathrm{CPB}$, heparinization was reversed with protamine sulphate at a ratio $1: 1$ with Heparin. 
Tab. 1: Preoperative characteristics of patients

\begin{tabular}{|l|l|l|l|l|}
\hline & MINI & ON & OFF & p \\
\hline No. of patients & 25 & 30 & 34 & \\
\hline Gender (no. of females/males) & $2 / 23$ & $5 / 25$ & $9 / 25$ & 0.193 \\
\hline Age (years; median, quartiles) & $69(63-73)$ & $67(61-71)$ & $68(61-74)$ & 0.807 \\
\hline BMI (median, quartiles) & $27(25-32)$ & $28(25-32)$ & $29(27-31)$ & 0.748 \\
\hline Ejection fraction (\%; median, quartiles) & $60(50-70)$ & $61(51-70)$ & $60(50-70)$ & 0.985 \\
\hline Diabetes mellitus (no.) & 7 & 10 & 8 & 0.977 \\
\hline COPD (no.) & 4 & 5 & 9 & 0.93 \\
\hline MI (no.) & 9 & 13 & 15 & 0.994 \\
\hline
\end{tabular}

Legend: BMI - Body Mass Index; COPD - Chronic Obstructive Pulmonary Disease; MI - Myocardial Infarction

Coronary Artery Bypass Grafting with Minimally Invasive Cardiopulmonary Bypass, mini on-pump technique

The sternotomy, heparinization and arterial cannulation were performed in standard fashion mentioned previously. For venous drainage a $22 \mathrm{~F}$ dual-stage venous cannula was placed via right atrium into the inferior vena cava and kinetic assisted drainage generated by centrifugal pump (KAVD) was applied. The minimally invasive CPB circuit (Minisystem Synergy, Sorin Group SrL, Mirandola, Italy) consisted of a very short internal face coated tubing (Phosphorylcholine) creating a closed loop, a venous bubble trap, a centrifugal pump, a membrane oxygenator, and $40.0 \mu \mathrm{m}$ arterial line filter. Cardiotomy suction device was not used. The priming of CPB circuit, pump flow, temperature management and surgical technique were similar to that described in conventional CPB. Retrograde autologous blood prime was used allowing displacement and removing of crystalloid prime by draining blood volume from patient into the circuit just before beginning CPB. Protection of the myocardium during surgery (blood cardioplegia and topical cooling) was the same as in the group of on-pump technique.

\section{Coronary Artery Bypass Grafting without Cardiopulmonary Bypass, off-pump technique}

All operations were performed via median sternotomy. Heparin was administered intravenously $(3 \mathrm{mg} / \mathrm{kg}$ of body weight) to maintain an activated clotting time (ACT) above $300 \mathrm{~s}$ during procedure. Patient was kept in normothermia. Exposure to the coronary arteries was performed with the use of suction tissue stabilizer OCTOPUS (Medtronic Inc., Minneapolis, MN, USA) and occasionally a retraction device STAR FISH (Medtronic Inc., Minneapolis, MN, USA) Target coronary arteries were snared proximally and distally using a silastic air-cushioned vascular loop RETRACTO-TAPE (Quest Medical, Inc., Allen, TX, USA). The operating field was kept free of blood with a humidified $\mathrm{CO}_{2}$ blower (Medtronic Inc., Minneapolis, MN, USA). Distal anastomoses were performed on the beating heart in a standard manner (every patient received left internal mammary artery graft and different number of saphenous vein grafts). A variety of commercially available intracoronary shunts were used at discretion of the operator. Proximal anastomoses were accomplished while a partial occlusion aortic clamp was applied. Heparinization was then reversed with protamine sulphate at a ratio $0.5: 1$ with Heparin.

Anesthesiological management has been described previously (12).

\section{Flow Cytometry}

Expression of TLR2 and TLR4 was measured on monocytes and granulocytes in venous blood samples. To distinguish between monocytes and granulocytes, staining of cell-surface TLR was performed with the combination of monoclonal antibodies as follows: TLR4 PE/CD14 PerCP/ CD45 APC and TLR2 PE/CD14 PerCP/CD45 APC. TLR4 PE, clone HTA125, and TLR2 PE, clone TLR2.3 was purchased from Serotec, while CD14 PerCP, clone МФР9 was from BD. CD45 APC, clone MEM-28 was purchased from Exbio. All samples were processed immediately upon the blood collection and the expression was measured within $2 \mathrm{~h}$ after the collection. A detailed method is described elsewhere (13).

Expression of the receptors was characterized with median fluorescence intensity (MFI), which was set on the basis of background fluorescence of the unstained control sample and the sample stained with isotype control.

\section{Statistics}

Statistics of flow cytometric parameters was computed to assess differences both within each group of patients and between all three groups.

Data distribution and homogeneity of variances was tested with Shapiro-Wilk test and Levene's test, respectively. To accept or reject possibility that there are no changes in any given flow cytometric parameters within a group, 
values measured during and after surgery were compared to values before surgery using Friedman ANOVA along with Wilcoxon pair test or the sign test. Differences between the groups were determined by Kruskal-Wallis ANOVA or median test. Since the sampling points during surgery matched only between mini on-pump and on-pump group, additionally these groups were compared by Mann-Whitney $U$ test or Kolmogorov-Smirnov test. To assess relationship between values measured at different time points, Spearman's rank coefficient was calculated.

Clinical parameters, which describe each group of patients, were compared using analysis of variance or Kruskal-Wallis ANOVA, and Pearson's X ${ }^{2}$ test or Freeman-Halton extension of Fisher's exact test. Differences in duration of cardiopulmonary bypass as well as in duration of aortic clamping between mini on-pump and on-pump group were assesed with Kolmogorov-Smirnov test.

Differences were considered significant if probability (p) was lower than 0.05. Bonferroni correction was applied in case of multiple comparisons. We used Statistica 10 software (StatSoft) to perform the test and plot the results.

In tables, analyzed parameters are characterized by the median value with inter-quartile range in brackets for every single time point. Comparisons within groups are included in tables, and they are described by obtained $\mathrm{p}$ value.

\section{Results}

\section{TLR4 granulocytes}

The expression of TLR4 is relatively weak on granulocytes, but this feature arises from the function of TLR4 on neutrophils that outnumber other immune cells.

Even though the expression was weak, we observed not only the significant increase but also the significant decrease of the expression of TLR4 at the time points we followed in our patients. The course in expression of TLR4 was similar on granulocytes after surgery in all three groups of patients. There was a significant decrease of expression at the end of surgery in every patient. In mini on-pump and on pump patients, we could also see the gradual decrease of expression during surgery, while after the end of surgery, the expression was increasing. The highest values of expression were measured on the 3rd day after surgery. Off pump patients reached higher values on the 1st, 3rd and 7 th day after surgery when compared with other groups. This difference was not statistically significant, but still surprising considering the fact that off-pump surgery supposedly activates immune cells to lesser extent than other techniques. Looking at the preoperative data, we can also exclude possibility that granulocytes in off-pump patients were activated before surgery (Tab. 3).

\section{TLR4 monocytes}

Changes in expression of TLR4 on monocytes were similar to the changes on granulocytes at the observation times. However, the difference between both populations of cells was the stronger expression of TLR4 on monocytes.

The expression was significantly decreased at the end of surgery, while on the 3rd and 7th day, the expression was enhanced with the maximum on the 3rd day after surgery in all groups of patients. This increase was significant only on the 3rd postoperative day in on-pump and off-pump patients.

Again, there was a significant decrease of expression during surgery in on-pump and mini on-pump group that might be attributed to the shedding of the TLR4 molecule from the cell surface.

Similarly to the expression of TLR4 on granulocytes, offpump patients also reached the highest expression of TLR4 on monocytes on the 3rd day after surgery when compared with other groups of patients. However, this difference was not significant and there were no differences in any other matching time points between all three groups (Tab. 4).

\section{TLR2 granulocytes}

TLR2 as well as TLR4 agonists are potent stimulators of granulocyte activation. In connection with this effect, they also suppress granulocyte apoptosis. Likewise the ex-

Tab. 2: Intraoperative and postoperative characteristics of patients

\begin{tabular}{|l|l|l|l|l|}
\hline & MINI & ON & OFF & $p$ \\
\hline No. of patients & 25 & 30 & 34 & \\
\hline Duration of surgery (min; median, quartiles) & $165(154-205)$ & $218(181-255)$ & $165(130-190)$ & 0.0003 \\
\hline Duration of bypass (min; median, quartiles) & $62(55-88)$ & $85(59-119)$ & - & $<0.05$ \\
\hline Duration of aortic clamping (min; median, quartiles) & $36(29-41)$ & $40(31-57)$ & - & $>0.05$ \\
\hline Anastomoses (no. median, quartiles) & $2(2-3)$ & $3(2-3)$ & $2(1-2)$ & $<0.0001$ \\
\hline Sepsis (no.) & 1 & 1 & 1 & 1 \\
\hline Renal insufficiency (no.) & 2 & 2 & 1 & 0.623 \\
\hline Acute myocardial infarction (no.) & 1 & 1 & 2 & 1 \\
\hline Multiorgan failure (no.) & 1 & 0 & 0 & 0.281 \\
\hline
\end{tabular}


Tab. 3: Expression of TLR4 on granulocytes

\begin{tabular}{|l|l|l|l|l|l|l|l|}
\hline & Before surg. & Start of CPB & End of CPB & End of surg. & 1st day & 3rd day & 7 th day \\
\hline Mini on-pump & $\begin{array}{l}11.5 \\
(10.4-12.3)\end{array}$ & $\begin{array}{l}10.7 \\
(9.8-12.3)\end{array}$ & $\begin{array}{l}9.6 \\
(8.9-10.3)\end{array}$ & $\begin{array}{l}9.5 \\
(8.7-10)\end{array}$ & $\begin{array}{l}11.6 \\
(11.1-13.2)\end{array}$ & $\begin{array}{l}14.6 \\
(12-18.8)\end{array}$ & $\begin{array}{l}12.6 \\
(10.6-14.9)\end{array}$ \\
\hline & & & $\mathrm{p}<0.001$ & $\mathrm{p}<0.001$ & & $\mathrm{p}<0.05$ & \\
\hline On-pump & $\begin{array}{l}13.5 \\
(11.2-16.1)\end{array}$ & $\begin{array}{l}11.4 \\
(10.2-12.7)\end{array}$ & $\begin{array}{l}10 \\
(9.3-11.2)\end{array}$ & $\begin{array}{l}10.9 \\
(9.2-11.2)\end{array}$ & $\begin{array}{l}12.6 \\
(10.7-14.3)\end{array}$ & $\begin{array}{l}15.9 \\
(12.7-21.5)\end{array}$ & $\begin{array}{l}13.3 \\
(10.7-15.2)\end{array}$ \\
\hline & & $\mathrm{p}<0.05$ & $\mathrm{p}<0.001$ & $\mathrm{p}<0.001$ & & & \\
\hline Off-pump & $\begin{array}{l}12.7 \\
(11.1-14.7)\end{array}$ & - & - & $\begin{array}{l}10.1 \\
(9.1-11.6)\end{array}$ & $\begin{array}{l}15.5 \\
(13.3-17.4)\end{array}$ & $\begin{array}{l}18.0 \\
(14.2-21.7)\end{array}$ & $\begin{array}{l}14.2 \\
(12-17.3)\end{array}$ \\
\hline & & & & $\mathrm{p}<0.001$ & & $\mathrm{p}<0.001$ & \\
\hline
\end{tabular}

Tab. 4: Expression of TLR4 on monocytes

\begin{tabular}{|l|l|l|l|l|l|l|l|}
\hline & Before surg. & Start of CPB & End of CPB & End of surg. & 1st day & 3rd day & 7 th day \\
\hline Mini on-pump & $\begin{array}{l}20.3 \\
(16-24.2)\end{array}$ & $\begin{array}{l}15.7 \\
(14-18.9)\end{array}$ & $\begin{array}{l}13.4 \\
(12.7-16.4)\end{array}$ & $\begin{array}{l}14.0 \\
(12.4-16.5)\end{array}$ & $\begin{array}{l}20.5 \\
(17-26.2)\end{array}$ & $\begin{array}{l}25.3 \\
(20.1-30.3)\end{array}$ & $\begin{array}{l}23.9 \\
(17.8-30)\end{array}$ \\
\hline & & $\mathrm{p}<0.001$ & $\mathrm{p}<0.001$ & $\mathrm{p}<0.001$ & & & \\
\hline \multirow{2}{*}{ On-pump } & $\begin{array}{l}22.1 \\
(18.3-31.6)\end{array}$ & $\begin{array}{l}17.7 \\
(15.4-23)\end{array}$ & $\begin{array}{l}16.5 \\
(14.4-19.6)\end{array}$ & $\begin{array}{l}15.6 \\
(14.5-17.7)\end{array}$ & $\begin{array}{l}20.1 \\
(17.9-31.4)\end{array}$ & $\begin{array}{l}26.8 \\
(21.3-37.4)\end{array}$ & $\begin{array}{l}23.3 \\
(18-30.1)\end{array}$ \\
\hline & & $\mathrm{p}<0.001$ & $\mathrm{p}<0.001$ & $\mathrm{p}<0.001$ & & $\mathrm{p}<0.05$ & \\
\hline Off-pump & $\begin{array}{l}25.4 \\
(20.6-32.1)\end{array}$ & - & - & $\begin{array}{l}18 \\
(15.4-31.8)\end{array}$ & $\begin{array}{l}25.1 \\
(19.8-36)\end{array}$ & $\begin{array}{l}35.6 \\
(25.9-43)\end{array}$ & $\begin{array}{l}30.5 \\
(25.2-39.5)\end{array}$ \\
\hline & & & & $\mathrm{p}<0.001$ & & $\mathrm{p}<0.05$ & \\
\hline
\end{tabular}

Tab. 5: Expression of TLR2 on granulocytes

\begin{tabular}{|l|l|l|l|l|l|l|l|}
\hline & Before surg. & Start of CPB & End of CPB & End of surg. & 1st day & 3rd day & 7 th day \\
\hline Mini on-pump & $\begin{array}{l}12.3 \\
(11.1-13)\end{array}$ & $\begin{array}{l}10.9 \\
(9.9-11.7)\end{array}$ & $\begin{array}{l}9.4 \\
(8.9-10.6)\end{array}$ & $\begin{array}{l}9.5 \\
(8.4-10.1)\end{array}$ & $\begin{array}{l}12.1 \\
(10.8-13.3)\end{array}$ & $\begin{array}{l}15.7 \\
(12.8-19)\end{array}$ & $\begin{array}{l}12.8 \\
(11.5-15.2)\end{array}$ \\
\hline & & & $\mathrm{p}<0.001$ & $\mathrm{p}<0.001$ & & $\mathrm{p}<0.001$ & \\
\hline On-pump & $\begin{array}{l}14.1 \\
(12.5-16.7)\end{array}$ & $\begin{array}{l}12.2 \\
(10.6-13.6)\end{array}$ & $9.9(8.8-11)$ & $9.7(8.4-11)$ & $\begin{array}{l}12.7 \\
(10.3-14.3)\end{array}$ & $\begin{array}{l}19.8 \\
(16.4-23.3)\end{array}$ & $\begin{array}{l}12.8 \\
(11.2-15.7)\end{array}$ \\
\hline & & $\mathrm{p}<0.05$ & $\mathrm{p}<0.01$ & $\mathrm{p}<0.01$ & & $\mathrm{p}<0.05$ & \\
\hline Off-pump & $\begin{array}{l}13.3 \\
(11.4-16.2)\end{array}$ & - & - & $\begin{array}{l}9.6 \\
(8.1-11.6)\end{array}$ & $\begin{array}{l}14.9 \\
(11.5-15.8)\end{array}$ & $\begin{array}{l}18.7 \\
(16.3-21.1)\end{array}$ & $\begin{array}{l}14.2 \\
(12.5-17.3)\end{array}$ \\
\hline & & & & $\mathrm{p}<0.001$ & & $\mathrm{p}<0.001$ & \\
\hline
\end{tabular}

pression of TLR4, the expression of TLR2 in granulocyte population is less pronounced than in the population of monocytes.

At the end of surgery, the expression of TLR4 was significantly decreased in all groups. The decrease in expression was also possible to observe during surgery in mini on-pump and on-pump patients. In sharp contrast to the profound decrease by the end of surgery, TLR4 was greatly upregulated on the 3rd postoperative day. On the 1 st and 7th day after surgery, the expression of TLR was around preoperative values.
In spite of median value of the expression being lower in mini on-pump patients than in other two groups on the 3rd day after surgery, there was not statistically significant difference between all three groups (Tab. 5).

\section{TLR2 monocytes}

TLR2 is expressed on monocytes in high density. In post-operative period however, we did not see a great enhancement in the expression of TLR2 on monocytes. The course of expression of TLR2 resembled of the expression 
Tab. 6: Expression of TLR2 on monocytes

\begin{tabular}{|l|l|l|l|l|l|l|l|}
\hline & Before surg. & Start of CPB & End of CPB & End of surg. & 1st day & 3rd day & 7 th day \\
\hline \multirow{2}{*}{ Mini on-pump } & $\begin{array}{l}34.9 \\
(25.8-48.3)\end{array}$ & $\begin{array}{l}24.8 \\
(17.9-30.1)\end{array}$ & $\begin{array}{l}19.5 \\
(15.2-24.3)\end{array}$ & $\begin{array}{l}17.5 \\
(14-25)\end{array}$ & $\begin{array}{l}44.2 \\
(37.2-54.8)\end{array}$ & $\begin{array}{l}39.7 \\
(29.7-58.5)\end{array}$ & $\begin{array}{l}35.4 \\
(26.6-49.5)\end{array}$ \\
\hline & & $\mathrm{p}<0.001$ & $\mathrm{p}<0.001$ & $\mathrm{p}<0.001$ & & & \\
\hline \multirow{2}{*}{ On-pump } & $\begin{array}{l}42.1 \\
(32.7-49.5)\end{array}$ & $\begin{array}{l}30.3 \\
(25-37.2)\end{array}$ & $\begin{array}{l}25.6 \\
(16-33.2)\end{array}$ & $\begin{array}{l}16.6 \\
(14.3-22.6)\end{array}$ & $\begin{array}{l}49.6 \\
(34.4-62.7)\end{array}$ & $\begin{array}{l}52.8 \\
(39.9-60.2)\end{array}$ & $\begin{array}{l}36.6 \\
(27.4-48.8)\end{array}$ \\
\hline & & $\mathrm{p}<0.001$ & $\mathrm{p}<0.001$ & $\mathrm{p}<0.001$ & & & \\
\hline \multirow{2}{*}{ Off-pump } & 44.4 & - & - & $\begin{array}{l}21 \\
(18.2-32.7)\end{array}$ & $\begin{array}{l}52.3 \\
(47.7-64.1)\end{array}$ & $\begin{array}{l}58.3 \\
(45.6-88.2)\end{array}$ & $\begin{array}{l}47.2 \\
(36-56.2)\end{array}$ \\
\hline & $(35.3-53)$ & & & $\mathrm{p}<0.001$ & & $\mathrm{p}<0.05$ & \\
\hline
\end{tabular}

of TLR4 on monocytes. There was a significant decrease in the expression during surgery and at the end of surgery in mini on-pump and on-pump group. Also in off-pump patients, the expression at the end of surgery was low compared to preoperative values. On postoperative days, TLR2 on monocytes was not up-regulated with exception of offpump group that reached significantly higher expression on the 3rd day after surgery in comparison to preoperative values $(\mathrm{p}<0.05)$ as well as in comparison with other two groups of patients $(\mathrm{p}<0.01)$ (Tab. 6).

Tab. 7: Correlation of expression of TLR2 or TLR4 between preoperative values and values during and after surgery

\begin{tabular}{|c|c|c|c|c|}
\hline $\begin{array}{l}\text { TLR4 on } \\
\text { granulocytes }\end{array}$ & $\begin{array}{l}\text { Start of } \\
\text { CPB }\end{array}$ & $\begin{array}{l}\text { End of } \\
\text { CPB }\end{array}$ & $\begin{array}{l}\text { End of } \\
\text { surg. }\end{array}$ & $\begin{array}{l}1 \text { st post } \\
\text { day }\end{array}$ \\
\hline Mini on-pump & 0.50 & 0.50 & 0.58 & \\
\hline On-pump & 0.78 & 0.68 & 0.70 & \\
\hline Off-pump & - & - & 0.61 & \\
\hline \multicolumn{5}{|l|}{$\begin{array}{l}\text { TLR4 on } \\
\text { monocytes }\end{array}$} \\
\hline Mini on-pump & 0.80 & 0.80 & 0.80 & 0.52 \\
\hline On-pump & 0.79 & 0.72 & 0.69 & 0.68 \\
\hline Off-pump & - & - & 0.76 & 0.64 \\
\hline \multicolumn{5}{|l|}{$\begin{array}{l}\text { TLR2 on } \\
\text { granulocytes }\end{array}$} \\
\hline Mini on-pump & & & 0.59 & \\
\hline On-pump & & & 0.61 & \\
\hline Off-pump & - & - & 0.50 & \\
\hline \multicolumn{5}{|l|}{$\begin{array}{l}\text { TLR4 on } \\
\text { monocytes }\end{array}$} \\
\hline Mini on-pump & & & 0.61 & \\
\hline On-pump & & & 0.57 & \\
\hline Off-pump & - & - & 0.59 & \\
\hline
\end{tabular}

Legend: The correlation is expressed using the Spearman coefficient.
Expression of TLR4 on granulocytes and monocytes displayed relationship between preoperative values and values at the end of surgery $\left(r_{s}=0.59\right.$ to 0.8$)$ in all groups of patients. Moreover, there was also correlation between preoperative TLR4 values on monocytes and the values on the 1 st day after surgery in all groups. In on-pump and mini on-pump patients, we could also observe relationship between preoperative values of TLR4 and the values during surgery $\left(r_{s}=0.5\right.$ to 0.8$)$, even though it was weaker on granulocytes in mini on-pump group $\left(\mathrm{r}_{\mathrm{s}}=0.5\right)$ (Tab. 7).

Preoperative values of TLR2 were correlated only with values at the end of surgery $\left(r_{s}=0.5\right.$ to 0.61$)$ both in granulocytes and monocytes. Although all groups showed the correlation, for off-pump patients it was the weakest $\left(r_{\mathrm{s}}=0.5\right)$ (Tab. 7).

Remarkably, we also found association between expression of TLR4 and TLR2 for both populations of myeloid cells. While the correlation between TLR4 and TLR2 was significant at the end of CPB, end of surgery, and on the 1st and 3 rd postoperative day in on-pump and mini on-pump patients, in off pump patients, such relationship existed only on the 1 st and 3rd day in monocytes, and on the 3rd day in granulocytes (Tab. 8).

In a subgroup of 5 on-pump patients, we performed the combination of cell surface staining with intracellular stain-

Tab. 8: Correlation between TLR4 and TLR2

\begin{tabular}{|l|l|l|l|l|}
\hline Granulocytes & $\begin{array}{l}\text { End of } \\
\text { CPB }\end{array}$ & $\begin{array}{l}\text { End of } \\
\text { surg. }\end{array}$ & $\begin{array}{l}\text { 1st post } \\
\text { day }\end{array}$ & $\begin{array}{l}\text { 3rd post } \\
\text { day }\end{array}$ \\
\hline Mini on-pump & 0.51 & 0.59 & 0.61 & 0.78 \\
\hline On-pump & 0.57 & 0.51 & 0.72 & 0.69 \\
\hline Off-pump & - & & & 0.56 \\
\hline Monocytes & & & & \\
\hline Mini on-pump & 0.57 & 0.50 & 0.68 & 0.71 \\
\hline On-pump & 0.73 & 0.73 & 0.74 & 0.77 \\
\hline Off-pump & - & & 0.62 & 0.76 \\
\hline
\end{tabular}

Legend: The correlation between TLR4 and TLR2 is expressed using the Spearman coefficient. 
ing and compared the results with the cell surface staining only. We observed cytoplasmatic expression of TLR4 and TLR2 in both granulocytes and monocytes (Fig. 1A-D). The highest cytoplasmatic expression of TLR4 and TLR2 was measured on the 1st day after surgery in both populations of cells, even though very high expression of intracellularly localized receptor was detected in the case of granulocyte TLR2 at all sampling points (Fig. 1B). Since the cell surface expression of TLRs increased on the 3rd day after surgery, we could assume that intracellularly localized TLR was at least partially displaced to the outside

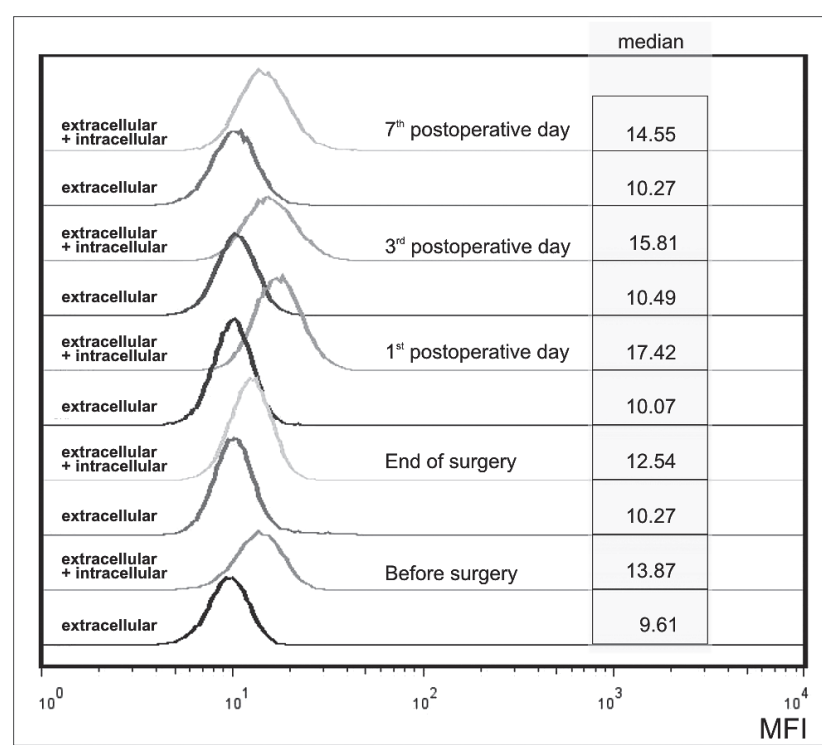

A) TLR4 in population of granulocytes

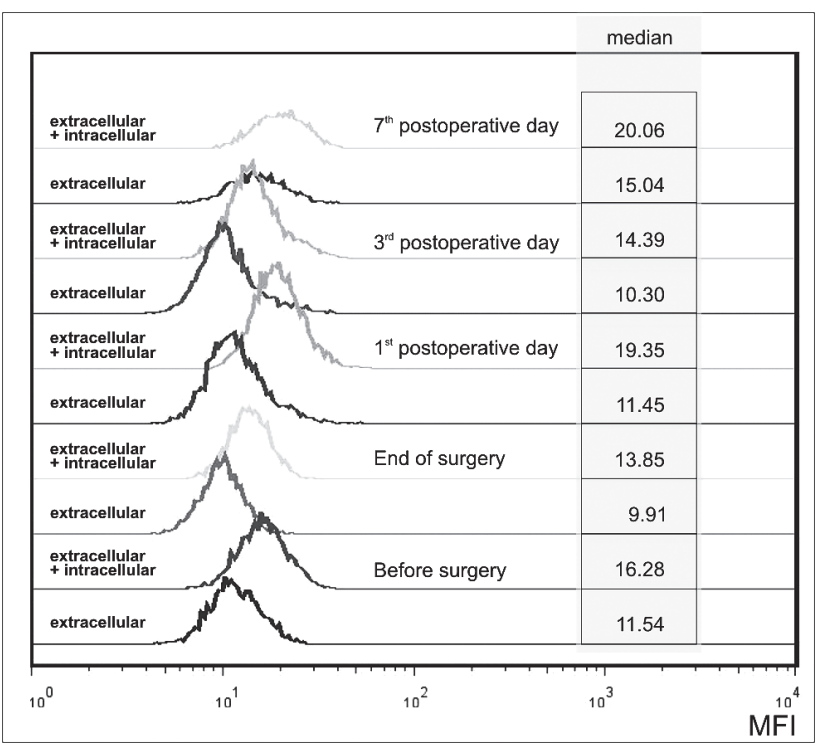

C) TLR4 in population of monocytes surface of plasma membrane. Since TLR4 and TLR2 are also expressed on membranes inside the cells, we combined cell surface staining with cytoplasmatic staining. Following the staining of cell surface antigens, we used $1 \%$ paraformaldehyde for $15 \mathrm{~min}$ to fix the surface proteins. Then the treatment with $0.5 \%$ saponin enabled us to perform the intracellular staining with monoclonal antibodies (light lines). The control samples were incubated with monoclonal antibodies prior to the paraformaldehyde and saponin treatment but the intracellular staining was not performed. These samples showed the expression of TLR in outside

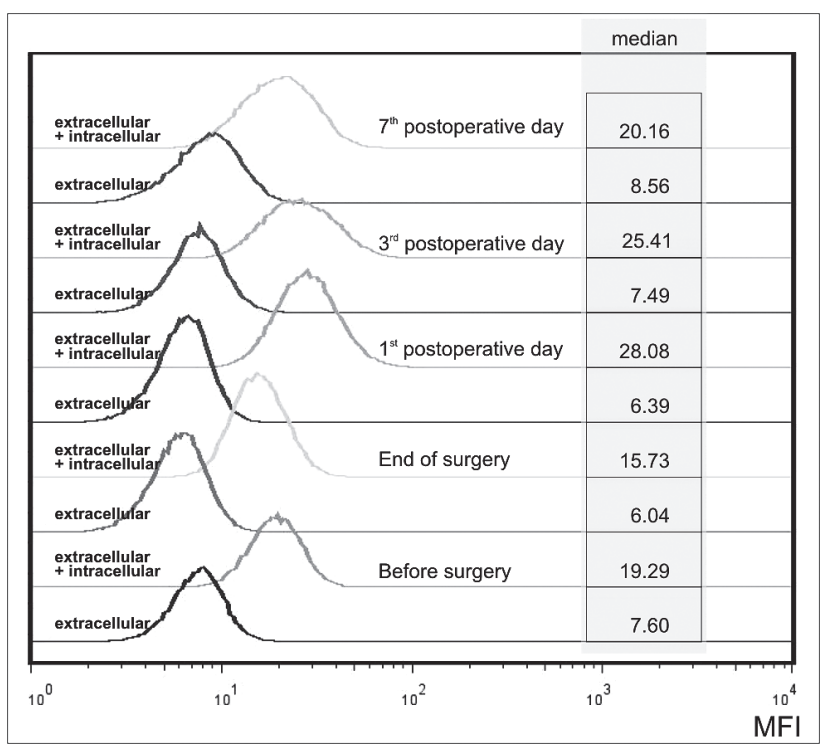

B) TLR2 in population of granulocytes

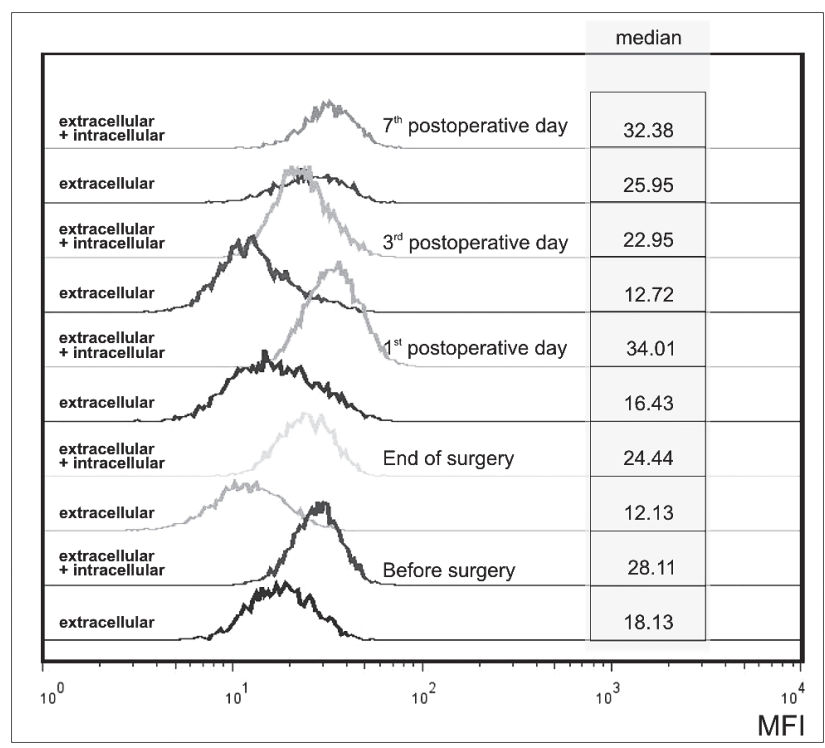

D) TLR2 in population of monocytes

Fig. 1: The example of a patient whose blood samples were stained with the combination of cell surface and intracellular staining 
plasma membrane (dark lines). Non-specific binding was prevented using the phosphate-buffered saline with $2.5 \mathrm{mM}$ EDTA, $0.2 \%$ BSA and 5\% FBS. Unstained and IgG control samples were used to reveal background fluorescence and the binding to Fc $\gamma$ receptors, respectively (data not shown).

\section{Discussion}

Acute inflammation directed by the innate immune response has evolved to efficiently combat infection and is critical to host defense. However, such innate mechanisms may also be activated as a result of tissue injury resulting from pathophysiological or exogenous sources. These events lead to what is termed a sterile inflammatory response (14). Patients who underwent cardiac surgery are exposed to both infectious and noninfectious danger stimuli the later being more pronounced in majority of cases.

There is a growing body of evidence linking TLRs, particularly TLR2 and TLR4, to the deleterious inflammatory effects seen in ischemia reperfusion injury associated with myocardial infection, and trauma, including cardiac surgery. This issue is recently reviewed by Arslan et al. (10). The modulation of TLR 2 and TLR4 expression on the peripheral blood monocytes and granulocytes of cardiac surgical patients with $\mathrm{CABG}$ was the matter of our interest of our previous research which results have already been published (11). We found that the intensity of both TLR2 and TLR4 is diminished during and after surgery. In this study we try to substantiate our previous result as only a few further studies aiming the dynamics of TLR receptors in CABG surgery have been published since the original observation of Dybhal et al. (15). In addition to our already published data on TLR4 and TLR2 dynamics in off-pump and on-pump patients, patients with modified CPB, "mini on-pump" patients were enrolled to this study.

Two different methods of CPB were compared in this study- standard CPB versus miniaturized CPB. Standard, conventional $\mathrm{CPB}$, which is daily used at our department, has no special chemical or biological coat on an internal tubing system surface. On the other hand the tubes of miniaturized CPB were coated by phosphorylcholine. We wanted to analyze different systems of CPB with all standard components in this study. That is why we did not use any coated tubing system for conventional CPB.

The expression of TLR receptors was determined by highly reproducible flow cytometry separately for blood granulocytes and monocytes. Both TLR2 and TLR4 on granulocytes was highly significantly diminished in all three groups of patients at the end of surgery regardless the use of CPB. It seems from this that CPB itself is not contributing substantially to the modulation of granulocyte TLR4 and TLR2 expression. It is a very surprising observation because there is the firm consensus that $\mathrm{CPB}$ is a strong inducer of granulocytes priming and activation (16). Thus, the very trauma associated with CABG surgery is responsible for TLR2 and TLR4 modulation on granu- locytes. The decrease in TLR2 and TLR4 expression was already significant at the end of CPB, it means, approximately 1 hour before the end of surgery suggesting that TLR2 and TLR4 down modulation is relatively early event in the course of cardiac surgery. The significantly decreased TLR2 and TLR4 expression on granulocytes at the end of surgery in patients operated with the use of CPB was reported by Hadley et al. (17). However, their group comprised six patients only who were followed up to the first postoperative day only.

The evaluation of TLR 2 and TLR4 expression on granulocytes is scarce. Neutrophils are considered to be predominantly effector cells in inflammatory response. Much interest is paid to monocyte/macrophages cells. This cells population is together with dendritic cells strategically distributed in blood and tissues serving as sentinel cells sensing both exogenous and endogenous harm stimuli by PRR receptors. Blood monocytes express all TLR receptors with higher density compared to granulocytes (18). Monocyte macrophages are the rich source of proinflammatory cytokines, such as IL- $1 \beta$, TNF $\alpha$, which are released early during inflammation. These cells are activated in tissue by surgical injury, local oxidative stress and by microbial PAMPs, such as bacterial lipopolysaccharides penetrating from gut microflora of cardiac surgical patients with transiently impaired gut mucosa immunity. The expression of TLR2 and TLR4 on monocytes was significantly diminished as early as at the start of CPB. In addition, there was no such apparent increase in TLR2 and TLR4 expression at the $3 \mathrm{rd}$ postoperative day on monocytes, compared to granulocytes. Thus monocytes seem to be the first leukocyte population which is stimulated by cardiac surgery. Decrease in TLR membrane receptors is mediated by either receptor internalization or shedding. Downmodulation of membrane receptors is relevant to the cells physiology. It is very likely that in cardiac surgical patients the exposition to proinflammatory stimuli is so extensive that various antiinflammatory homeostatic mechanisms are switch on to prevent the development of overwhelming inflammatory response. Indeed, several such protective mechanisms have already been described in cardiac surgery. The increase in IL-10 level which is recognized as antiinflammatory homeostatic cytokine after cardiac surgery is consistently reported $(12,19)$. Monocyte/macrophage population is functionally heterogeneous. The number monocytes expressing scavenger receptor for hemoglobin CD163 is increased early after cardiac surgery $(20,21)$. Macrophages expressing CD163 are designated as M2c subset. They are considered to dampen inflammatory response among other by the production of IL-10 and TGF beta as well as glucocorticoid signaling. The increased TLR2 and TLR4 expression on effector granulocyte population at the 3rd postoperative day is probably induced by elevated level of proinflammatory cytokines, e.g. TNF $\alpha$, which level is peaked early after cardiac surgery. Dybdahl et al. (15) in their early work found significantly decreased TLR2 expression on monocytes at 
the end of surgery with significant increase at the 2nd day after surgery. TLR4 expression was only non significantly decreased early after surgery with significant increase up to 2nd day after surgery when the observation was finished. Versteeg et al. (22) followed rather heterogeneous group of patients who underwent surgery on the heart arteries. These patients were examined during surgery up to the 1st postoperative day. In concordance with our results both TLR2 and 4 expression on monocytes was significantly diminished after surgery. In contrast to our results their expression was significantly increased already at the 1 st postoperative day. In our study this increase was postponed to the 3rd postoperative day. It is not possible to reconcile in this regards because in the third available work by Hadley (17) the observational period was finished again only $20 \mathrm{hrs}$ after surgery. In addition, the value of this work is limited by the fact that 6 patients only were enrolled. Various surgical traumas seem differently modulate TLR expression. Hei et al. (23) reported significantly increased TLR2 and TLR4 expression on blood mononuclear cells of patients with liver transplantation already at the first postoperative day. In contrast to these results, TLR2 and TLR4 expression was significantly diminished at that time in our cardiac surgical patients.

It is very difficult to interpret our observation that the significant relationship of TLR2 and TLR4 expression both on monocytes and granulocytes especially between preoperative values and values at the end of surgery was found. Remarkably, we also found association between TLR2 and TLR4 expression for both monocytes and granulocytes. These associations seem to be more pronounced in on-pump patients in comparison with off-pump patients probably reflecting the impact of CPB itself. Relevant data already published which address these issues are not available.

Original in essence seems our determination of both extracellular and intracellular TLR2 and TLR4 expression in the populations of monocytes and granulocytes in a subgroup of on-pump patients. TLR2 and TLR4 are considered to be membrane expressed. However, we found very high expression of intracellularly localized TLR2 in granulocytes at all observational points. The highest intracellularly localized expression of TLR 2 and TLR 4 both in monocytes and granulocytes was reached at the 1 st postoperative day when membrane expression of these receptors was similar to preoperative values being significantly diminished at the end of surgery. From this dynamics it seems unlikely that increased intracellular expression of TLR2 and TLR4 receptors is caused by receptors internalization. This increase is more likely the early physiological response reflecting body demand since the cell surface expression of TLR receptors is significantly increased at the 3 rd day after surgery. We could assume that intracellularly localized TLRs are displaced to the outside surface of plasma membrane. However, the possibility that intracellularly localized TLR2 and TLR4 receptors are also serving as PRR receptors of danger signals remains to be elucidated.
Recently, gene regulation network connecting ischemia/ reperfusion with systemic inflammation in cardiac surgery with CPB identified by whole blood transcriptomics was reported by Liangos et al. (24). They found the upregulation of key sensors of ischemia/reperfusion which activation initiated a concerted inflammatory response via upregulation of TLR4, 5, IL6, IL1beta/IL18, and pentraxin 3. The former components of immune response are recognized in cardiac surgery as prominent proinflammatory response elements. Pentraxin3 exerts antiinflammatory homeostatic activity (25) and is less pronounced than C-reactive protein increase after surgical procedures (26). In present study no significant differences in TLR2 and TLR4 expression between either on pump, mini on pump or off pump patients were found. Emerging data suggest that the inflammatory response is activated regardless the use of CPB (27).

In conclusion, the current concept of contact activation of leukocytes by CPB might be oversimplified. The proinflammatory response evoked by cardiac surgery is balanced by antiinflammatory and pro-survival response. The modulation of TLR2 and TLR4 expression on innate immunity cells of cardiac surgical patients described in this work is very likely the part of body effort to maintain homeostasis.

\section{Acknowledgements}

This work was supported by Charles University in Prague, Faculty of Medicine in Hradec Kralove, Czech Republic, project "PRVOUK" P37/10.

Disclosure: Authors declare no conflict of interest.

\section{References}

1. Chew MS, Brandslund I, Brix-Christensen V, et al. Tissue injury and the inflammatory response to pediatric cardiac surgery with cardiopulmonary bypass. Anesthesiology 2001; 94: 745-753.

2. Chowdhury UK, Malik V, Yadav R, et al. Myocardial injury in coronary artery bypass grafting: On-pump versus off-pump comparison by measuring high-sensitivity C-reactive protein, cardiac troponin I, heart-type fatty acid-binding protein, creatine kinase MB, and myoglobin release. J Thorac Cardiovasc Surg 2008; 135 : $1110-1119$.

3. Wang Y, Abarbanell AM, Herrmann JL, et al. Toll-like receptor signaling pathways and the evidence linking toll-like receptor signaling to cardiac ischemia/ reperfusion injury. Shock 2010; 34: 548-557.

4. Svitek V, Lonsky V, Mandak J, et al. No clear clinical benefit of using miniinvasive extracorporeal circulation in coronary artery bypass grafting in low risk patients. Perfusion 2009; 24: 263-269.

5. Biancari F and Rimpiläinen R. Meta-analysis of randomised trials comparing the effectiveness of miniaturised versus conventional cardiopulmonary bypass in adult cardiac surgery. Heart 2009; 95: 964-969.

6. Takagi H, Matsui M, Umemoto T. Off-pump coronary artery bypass may increase late mortality: a meta-analysis of randomized trials. Ann Thorac Surg 2010; 89: 1881-1888.

7. Piccinini AM, Midwood KS. DAMPening inflammation by modulating TLR signalling. Mediators Inflamm 2010; doi:10.1155/2010/672395.

8. C. Erridge. The roles of Toll-like receptors in atherosclerosis. J Innate Immun 2009; $1: 340-349$.

9. Hirsiger S, Simmen HP, Werner CM, et al. Danger signals activating the immune response after trauma. Mediators Inflamm 2012; doi:10.1155/2012/315941.

10. Arslan F, Keogh B, McGuirk P, et al. TLR2 and TLR4 in ischemia reperfusion injury. Mediators Inflamm 2010; doi:10.1155/2010/704202.

11. Krejsek J, Kunes P, Kolackova M, et al. Expression of Toll-like receptors 2 and 4 on innate immunity cells modulated by cardiac surgical operation. Scand J Clin Lab Invest 2008; 68: 749-758. 
12. Kolackova M, Krejsek J, Svitek V, et al. The effect of conventional and mini-invasive cardiopulmonary bypass on neutrophil activation in patients undergoing coronary artery bypass grafting. Mediators Inflamm 2012; doi: $10.1155 / 2012 / 152895$.

13. Jankovicova K, Kolackova M, Kunes P, et al. Interferon gamma receptor expression on granulocytes of cardiac surgical patients is modulated differently by the type of cardiopulmonary bypass. Perfusion 2012; $27: 49-55$.

14. Russell SE, Walsh PT. Sterile inflammation - do innate lymphoid cell subsets play a role? Front Immunol 2012; 3: 1-6.

15. Dybdahl B, Wahba A, Lien E, et al. Inflammatory response after open heart surgery release of heat-shock protein 70 and signaling through Toll-like receptor-4. Circulation 2002; 105: 685-690.

16. Franke A, Lante W, Fackeldey V, et al. Pro-inflammatory cytokines after differen kinds of cardio-thoracic surgical procedures: is what we see what we know? Eur J Cardiothorac Surg 2005; 28: 569-575.

17. Hadley JS, Wang JE, Michaels LC, et al. Alterations in inflammatory capacity and TLR expression on monocytes and neutrophils after cardiopulmonary bypass. Shock 27: 466-7473.

18. Williams HJ, Fisher EA, Greaves DR. Macrophage differentiation and function in atherosclerosis: opportunities for therapeutic intervention. J Innate Immun 2012; doi:10.1159/2012/000336618.

19. Kunes P, Lonsky V, Mandak J, et al. The long pentraxin 3 in cardiac surgery: distinct responses in "on-pump" and "of pump" patients. Scand Cardiovasc J 2007; 41: 171-179.
20. Krejsek J, Mandak J, Kunes P, et al. Impact of methylprednisolone in priming solution of cardiopulmonary bypass on antiinflammatory CD163 receptor during cardiac surgery. Perfusion 2012; 27: 284-291.

21. P. Philippidis P, Athanasiou T, Nadra I, et al. Anti-inflammatory haemoglobin scavenging monocytes are induced following coronary artery bypass surgery. Eur J Cardiothorac Surg 2010; 37: 1360-1366.

22. Versteeg D, Dol E, Hoefer IE, et al. Toll like receptor 2 and 4 response and expression on monocytes decrease rapidly in patients undergoing arterial surgery and are related to preoperative smoking. Shock $2009 ; 31: 21-27$.

23. Hei Z, Chi X, Cheng N, et al. Upregulation of TLR2/4 expression in mononuclear cells in postoperative systemic inflammatory response syndrome after liver transplantation. Mediators Inflamm 2010; doi:10.1155/2010/519589.

24. Liangos O, Domhan S, Schwager C, et al. Whole blood transcriptomics in cardiac surgery identifies a gene regulatory network connecting ischemia reperfusion with systemic inflammation. PLoS One 2010; 5: e13658.

25. Kunes P, Holubcova Z, Kolackova M, et al. Pentraxin 3(PTX 3): An endogenous modulator of the inflammatory response. Mediators Inflamm 2012; doi:10.1155/2012/920517.

26. Åkerfeldt T, Larsson A. Pentraxin 3 increase is much less pronounced than C-reactive protein increase after surgical procedures. Inflammation 2010; 34 : 367-370.

27. Castellheim A, Hoel TN, Videm V, et al. Biomarker profile in off-pump and onpump coronary artery bypass grafting surgery in low-risk patients. Ann Thorac Surg 2008; 85: 1994-2002.

Received: $14 / 03 / 2013$

Accepted in revised form: 02/05/2013

\section{Corresponding author:}

Jan Krejsek, University Hospital, Department of Clinical Immunology, Sokolská 581, 50005 Hradec Králové, Czech Republic; e-mail: krejsek@fnhk.cz 